\title{
PerCursos
}

\section{Big Data, Psicopolítica e Infoética: repercussões na cultura e na educação}

\section{Resumo}

Tendo por base as reflexões teóricas de Manuel Castells, Lucia Santaella, Byung-Chul Han, Luciano Floridi e Derrick de Kerckhove, o presente ensaio problematiza a dimensão ética da cultura digital, bem como os desafios de governos, academia e sociedade civil organizada diante das novas técnicas de poder instauradas como a sofisticação tecnológica que se convencionou chamar de 'Big Data'. Diante das transformações profundas que as tecnologias ubíquas vêm provocando na vida contemporânea, conclui-se que a ética da informação é essencial para discutirmos o bom uso das tecnologias digitais, bem como refletir os impactos no avanço exponencial da inteligência artificial e da governança cibernética sobre a vigilância dos algoritmos.

Palavras-chave: Comunicações digitais. Ética. Participação social - Vigilância eletrônica - Privacidade.

\section{Valdeci Reis \\ Doutor em Educação pela}

Universidade do Estado de Santa

Catarina - UDESC. Técnico em

Educação no Instituto Federal de santa Catarina - SC.

Brasil

valdeci.reis@ifsc.edu.br

\section{Roberta Fantin Schnell}

Doutoranda em Educação na Universidade do Estado de Santa Catarina - UDESC. Professora da rede de Florianópolis-SC.

Brasil

roberta.pmf@gmail.com

\section{Ademilde Silveira Sartori}

Doutora em Comunicação pela Universidade de São Paulo - USP.

Professora permanente do Programa de Pós-Graduação em

Educação da UDESC. Brasil

ademildesartori@gmail.com

\section{Para citar este artigo:}

REIS, Valdeci; SCHNELL, Roberta Fantin; SARTORI, Ademilde Silveira. Big Data, Psicopolítica e Infoética: repercussões na cultura e na educação. Revista PerCursos, Florianópolis, v. 21, n.45, p. 50 - 79, jan./abr. 2020.

DOI: $10.5965 / 1984724621452020050$

http://dx.doi.org/10.5965/1984724621452020050 


\title{
'Big Data', Psychopolitics and Infoetics: impact on culture and education
}

\begin{abstract}
Based on the theoretical reflections of Manuel Castells, Lucia Santaella, Byung-Chul Han, Luciano Floridi and Derrick de Kerckhove, this essay discusses the ethical dimension of digital culture, as well as the challenges of governments, the academic community and organized civil society in the face of new power strategies, such as the technological sophistication that was conventionally called 'Big Data'. In view of the profound transformations that ubiquitous technologies have been causing in contemporary life, we conclude that information ethics is essential to discuss the good use of digital technologies, as well as to reflect the impacts on the exponential advance of artificial intelligence and cyber governance on the surveillance of algorithms.
\end{abstract}

Keywords: Digital communications. Ethics. Social participation - surveillance - privacy. 


\section{Introdução: delineando alguns conceitos na cultura digital}

Um dos eventos mais importantes da área de educação nos Estados Unidos é a Reunião Anual da AERA - American Educational Research Association, que reúne pesquisadores, estudantes da pós-graduação e profissionais da educação básica. Trata-se de um evento similar às reuniões científicas da Associação Nacional de Pós-Graduação e Pesquisa em Educação - ANPEd, que ocorrem no Brasil. Em 2018, a cidade de Nova lorque (EUA) foi sede do evento, que teve como tema central: The dreams, possibilities, and necessity of public education (Os sonhos, possibilidades e necessidades da educação pública). Três grandes temas conduziram as discussões da AERA 2018: a intensificação da privatização da educação básica nos EUA; o papel da educação diante do que a imprensa americana rotula como "era da pós-verdade" e/ou disseminação de fake news; e a inusitada proposta do Presidente Donald Trump de armar os professores, uma estratégia de defesa contra os tiroteios cada vez mais comuns nas escolas americanas.

Iniciamos este ensaio recuperando os pontos centrais das discussões tecidas na reunião anual dos programas de pós-graduação em educação estadunidense para enfatizar que a necessidade de reflexão sobre a dimensão ética e estética das redes não é uma especificidade do Brasil, mas também dos países que estão no centro do Capitalismo.

Uma sociedade estruturada em rede (CASTELLS, 2010), ubíqua (SANTAELLA, 2013), de avanços significativos no campo da inteligência artificial ${ }^{1}$ - são as características que marcam o final da segunda década do século XXI. A perspectiva sociológica tem nos proporcionado importantes reflexões, teorias que se debruçaram a analisar o conceito de

\footnotetext{
1 A pesquisadora Dora Kaufman define a Inteligência Artificial como: "um campo de conhecimento associado à linguagem e à inteligência, ao raciocínio, à aprendizagem e à resolução de problemas. A IA propicia a simbiose entre humano e a máquina ao acoplar sistemas inteligentes artificiais ao corpo humano (prótese cerebral, braço biônico, células artificiais, joelhos inteligentes e similares) e a interação entre o homem e a máquina como duas 'espécies' distintas conectadas (homem-aplicativos, homemalgoritmos de IA). Os estágios de desenvolvimento, bem como as expectativas, variam entre os campos e suas aplicações, que incluem os veículos autônomos, reconhecimento de voz, games, robótica, tradução de linguagem natural, diagnósticos médicos, assim por diante." (KAUFMAN, 2019, p. 19-20).
} 
rede. Neste trabalho, o espanhol Manuel Castells foi a companhia que escolhemos para dialogar com o tema².

Em sua hercúlea trilogia, o autor define rede como um conjunto de pontos, uma espécie de rizoma3; trata-se de nós conectados por elementos que têm alguma relação entre si (CASTELLS, 1996; 1997; 1998). A base para a constituição de uma rede é o seu objetivo e a adesão de usuários; flexibilização das relações e interação instantânea são outras duas características importantes das redes, sobretudo quando nos referimos às redes sociais digitais. De acordo com o autor, "nó é o ponto no qual uma curva se entrecorta. Concretamente, o que seria um nó depende do tipo de redes concretas de que estamos falando" (CASTELLS, 2002, p. 566). De acordo com essa perspectiva sociológica, uma rede pode ser formada a partir de um partido político, na qual os nós pessoas que comungam de uma determinada ideologia, simpatizantes, empresários e especialistas em marketing político - se articulam e traçam estratégias para vencer uma eleição em um município, estado ou país. Na mesma medida, a rede pode surgir a partir da afinidade de alguns jovens, ou entidades estudantis que se organizam e mobilizam outras pessoas, por exemplo, para protestar contra o genocídio da juventude negra nas “quebradas" de um município. Pode, igualmente, nascer a partir de indivíduos de uma facção criminosa, que, com o apoio de alguns moradores de um determinado bairro, centros de distribuição, logística e monitoramento, acabam por obter o controle do tráfico de drogas ilícitas de uma determinada região geográfica de um país. Nas palavras do autor:

Redes são estruturas abertas capazes de se expandir de forma ilimitada, integrando novos nós desde que consigam comunicar-se dentro da rede, ou seja, desde que compartilhem os mesmos códigos de comunicação (por exemplo, valores ou objetivos de desempenho). Uma estrutura

\footnotetext{
${ }^{2}$ A bibliografia sobre a temática é múltipla e vasta. Leitores interessados em um panorama geral do assunto, conferir os trabalhos MACIEL, Kátia; PARENTE, André (orgs.). Redes sensoriais: arte, ciência e tecnologia. Rio de Janeiro: Contra Capa, 2003; PARENTE, André (org.). Tramas da rede. Porto Alegre: Sulina, 2004; DUARTE, Fábio; QUANDT, Carlos; SOUZA, Queila (orgs.). O tempo das redes. São Paulo: Perspectiva, 2008.

3 Recorrer à metáfora do rizoma para discutir o conceito de rede, aparece não apenas nas teorizações de Castells (2010), mas também nos trabalhos dos pesquisadores brasileiros Virgínia Kastrup (2010) e André Parente (2004). Nessa perspectiva, os 'nós' que estruturam a rede são conectáveis em todas as suas dimensões e direções; são também desmontáveis, reversíveis, suscetíveis de receber modificações instantaneamente.
} 
social com base em redes é um sistema aberto altamente dinâmico suscetível de inovação sem ameaças ao seu equilíbrio. (CASTELLS, 2002, p. 566).

É preciso ressaltar que, para o autor, a rede pode ser formada por humanos e não humanos. O avanço do desenvolvimento científico e tecnológico, bem como o uso de técnicas para o aprimoramento de atividades específicas, resultou nas tecnologias digitais. A rápida evolução da engenharia computacional que, por meio de arquiteturas de softwares e hardwares, permitiu a interligação e comunicação de diferentes engenharias tecnológicas - como, por exemplo: radiodifusão, redes telemáticas, redes de fibra óptica - e consolidou a era digital. O desenvolvimento da microeletrônica e o avanço no processo de convergência com a engenharia de telecomunicações resultaram no surgimento das tecnologias ubíquas. São artefatos tecnológicos móveis que, conectados à rede mundial de computadores, proporcionam interação - comunicação em rede - a qualquer momento, em qualquer espaço.

No Brasil, Lúcia Santaella é a pesquisadora que mais tem se dedicado a pesquisar e escrever sobre essa temática. Uma das teses defendidas pela autora é que o intenso desenvolvimento científico e tecnológico contribuiu para que a condição contemporânea da existência humana se tornasse ubíqua.

Em função da hipermobilidade, tornamo-nos seres ubíquos. Estamos, ao mesmo tempo, em algum lugar e fora dele. Tornamos intermitentemente pessoas presentes-ausentes. Aparelhos móveis nos oferecem a possibilidade de presença perpétua, de perto ou de longe, sempre presença. Somos abordados por qualquer propósito a qualquer hora e podemos estar em contato com outras pessoas quaisquer que sejam suas condições de localização e afazeres no momento, o que nos transmite um sentimento de onipresença. Corpo, mente e vida ubíquas. Sem dúvidas isso traz efeitos colaterais, certo estado de frenesi causado pelo paradoxo da presença e ao mesmo tempo da reviravolta constante nas várias condições físicas, psicológicas e computacionais. (SANTAELLA, 2013, p. 16). 
No campo da ciência da comunicação, o conceito de ubiquidade tem sido problematizado à luz de uma metáfora. Souza e Silva também colabora com uma importante síntese:

Tecnologicamente, a ubiquidade pode ser definida como a habilidade de se comunicar a qualquer hora e em qualquer lugar via aparelhos eletrônicos espalhados pelo meio ambiente. Idealmente, essa conectividade é mantida independentemente do movimento ou da localização da entidade. Essa independência da necessidade de localização deve estar disponível em áreas muito grandes para um único meio com fio, como, por exemplo, um cabo ethernet. Evidentemente, a tecnologia sem fio proporciona maior ubiquidade do que é possível com os meios com fio, especialmente quando se dá em movimento. Além do mais, muitos servidores sem fios espalhados pelo ambiente permitem que o usuário se mova livremente pelo espaço físico sempre conectado. (SOUZA E SILVA, 2006, p. 179).

Desde que a World Wide Web foi implantada, e isso ocorreu há apenas três décadas, as tecnologias digitais foram penetrando nas nossas residências, estações de trabalho, salas de aula das escolas e universidades, fornecendo informações, serviços e mobilidades de acordo com a necessidade de cada usuário. Desde 2010, se intensificou o uso do Big Data, ou seja, uma engenharia robótica capaz de analisar grandes volumes de transações na rede em questões de segundos, para monitorar tendências e comportamentos populacionais. Estudos têm sido movidos por um desconforto no que se refere aos aspectos da privacidade, alertando para a necessidade de uma profunda reflexão ética e estética das redes (SANTAELLA, 2016b; 2018; KERCKHOVE, 2016; HAN, 2014; 2019; REIS, 2020).

A complexidade da arquitetura das redes digitais tem instigado debates acadêmicos dos mais variados espectros ideológicos. Neste ensaio, recorremos às análises tecidas pela filósofa Shoshana Zuboff, professora emérita da Universidade de Harvard, para definir o conceito da tecnologia Big Data:

O big data é constituído pela captura de small data, das ações e discursos, mediados por computador, de indivíduos no desenrolar da vida prática. 
Nada é trivial ou efêmero em excesso para essa colheita: as 'curtidas' do Facebook, as buscas no Google, e-mails, textos, fotos, músicas e vídeos, localizações, padrões de comunicação, redes, compras, movimentos, todos os cliques, palavras com erros ortográficos, visualizações de páginas e muito mais. Esses dados são adquiridos, tornados abstratos, agregados, analisados, embalados, vendidos, analisados mais e mais e vendidos novamente. (ZUBOFF, 2018, p. 31-32).

O modo como as redes digitais estão tecnologicamente estruturadas faz com que toda ação tecida no ciberespaço deixe rastros. Essa versão renovada de sociedade do controle transforma cada movimento executado pelos internautas em dados valiosos, para o que Lúcia Santaella (2016b, p. 90) denomina de capitalismo digital, ou seja, a economia governada por algoritmos: "nada mais no universo escapa a lógica do seu poder invisível e onipresente". Mais do que espaços de colaboração e criação, a infosfera está se transformando em uma versão digital do projeto "panóptico", proposto em 1785 pelo filósofo e jurista britânico Jeremy Bentham. ${ }^{4}$

O "panóptico" de Bentham, imaginado para depositar um poder inquestionável nas mãos das autoridades, baseava-se nessa reversão: Sua essência, escreveu o filósofo, repousa "na centralidade da situação do inspetor" combinada com "as mais eficazes ferramentas para ver sem ser visto". Em uma democracia saudável acontece o contrário. Democracia exige prestação de contas e consentimento dos governados, o que só é possível quando os cidadãos sabem o que está sendo feito em seu nome. A pressuposição, com raras exceções, é de que eles saberão tudo o que suas autoridades políticas estiverem fazendo; é por isso que essas autoridades são chamadas de funcionários públicos e trabalham no setor público, no serviço público e em órgãos públicos. De forma inversa, também com raras exceções, a pressuposição é que o governo não saberá nada que os cidadãos respeitadores da lei estiverem fazendo. É por isso que somos chamados de indivíduos privados, que operam na esfera privada. A transparência é para quem cumpre funções públicas e exerce um poder público. A privacidade é para todos os demais. (GREENWALD, 2014, p. 220-221).

\footnotetext{
4 Leitores interessados na temática, conferir "O panóptico" (BENTHAM, 2000) e Vigiar e Punir (FOUCAULT, Michel. Vigiar e punir: o nascimento da prisão. Petrópolis: Vozes, 1977).
} 
Glenn Greenwald formulou a análise citada acima ao escrever sobre os documentos oficiais do governo norte-americano, trazidos a público em julho de 2013 por Edward Snowden, comprovando a vigilância ilimitada colocada em curso pela Agência de Segurança Nacional (NSA). Os arquivos em poder do ex-funcionário da CIA revelaram ao mundo que o monitoramento em massa atingiu não apenas os americanos, mas também várias autoridades de países, alguns inclusive aliados dos Estados Unidos entre 2007 e 2009 (SNOWDEN, 2019). Tais revelações desencadearam no meio acadêmico, jurídico e político um amplo debate sobre o direito à privacidade, bem como os limites da vigilância governamental.

No atual estágio da cultura digital, o grande analista que tudo monitora é o algoritmo5; nada mais escapa ao seu monitoramento ubíquo. Empresas, governos, servidores públicos, a cultura, nossos hábitos, nossos pensamentos, nossas decisões são movidos pela governança algorítmica.

Portanto, a vigilância ubíqua e invisível, agora sustentada pelos algoritmos, não é outra coisa senão um incremento, uma sofisticação e refinamento da economia política no capitalismo digital. Assim, a biopolítica, que encontra hoje nos algoritmos, nos big data, seus maiores coadjuvantes, tem a ver com o poder que, regulado pela política científica, medicinal e jurídica, é exercido sobre a biologia, sobre a vida das populações que crescem cada vez mais, ocupando todos os espaços disponíveis sobre o globo. (SANTAELLA, 2016a, p. 100).

Este ensaio, dividido em três seções, tem como objetivo tecer algumas reflexões sobre a ambivalência - transparência x vigilância - diante da popularização da sofisticação tecnológica que se convencionou a denominar de Big Data. Diante das novas assimetrias de poder instauradas no capitalismo digital, advogamos que uma reflexão

\footnotetext{
5 De acordo com Dora Kaufman (2019, p. 34-35), “Algoritmo é um conjunto de instruções matemáticas, uma sequência de tarefas para alcançar um resultado esperado em um tempo limitado. Os algoritmos antecedem os computadores - o termo remonta ao século IX, ligado ao matemático Al-Khwãrismi, cujo livro ensinava técnicas matemáticas a serem equacionadas manualmente. 'Algorismus' era originalmente o processo de calcular numerais hindo-arábicos”. Na cultura digital, trata-se de uma sequência lógica que permite comandos autônomos de processos informatizados.
} 
ética sobre o uso dos dados informacionais se torna urgente por parte de governos, sociedade civil organizada e instituições de ensino.

\section{Big Data e suas assimetrias de poder: algumas reflexões à luz da filosofia de Byung-Chul Han}

O avanço das tecnologias da informação e comunicação tem sido analisado na academia sob diferentes perspectivas. Nesta seção, trazemos para o debate os ensaios filosóficos do professor da Universität der Künste Berlin, Byung-Chul Han. Sua biografia é marcada por algumas curiosidades: nasceu em Seul, em 1959, onde estudou o Curso Técnico Profissionalizante em Metalurgia. Aos 30 anos, movido por uma obsessão incontrolável de estudar literatura, abandonou seu país e ingressou na Universidade de Teologia, em Munique, mesmo não dominando o idioma alemão. Mais tarde mudou para a Universidade de Friburgo, onde passou a estudar Filosofia.

Declara-se seguidor de Giorgio Agamben e, em 1994, doutorou-se na Universidade de Munique com uma tese sobre Martin Heidegger. Em seus artigos é possível identificar forte influência desses dois filósofos nas análises teóricas que sustentam seus argumentos. Publica uma média de dois a três livros por ano, todos recebidos com fervor pelo meio acadêmico europeu. Nos parágrafos abaixo, será apresentada uma síntese dos livros em que o filósofo discorre sobre os desafios humanos no contemporâneo, com a disseminação da cultura digital.

Síndrome do pânico, déficit de atenção, hiperatividade, transtorno de personalidade, síndrome de Burnout, são algumas das patologias psíquicas que marcam a Sociedade do Cansaço (HAN, 2017), título da primeira obra do autor que repercutiu na América Latina. Nesse livro, Han destaca que a história da humanidade evoluiu superando as enfermidades típicas de cada era. Ele argumenta que, embora o desenvolvimento científico tenha avançado significativamente para conter as enfermidades bacterianas e virais, um dos maiores desafios do nosso tempo é superar as enfermidades neurais. Complicações psíquicas, excesso de voyeurismo, competição consigo mesmo, dificuldade 
de discernimento entre as esferas pública e privada são alguns dos dilemas com que os usuários imersos na rede se confrontam diariamente.

Nesse ensaio, o filósofo discorre sobre a transição de uma sociedade disciplinar fundada nas escolas, cadeias, fábricas e igrejas - para uma sociedade do desempenho, estruturada nos centros de manipulação genética, espaços fitness e dopagem biofármaca. Cada infonauta é, agora, empresário de si mesmo, um automutilador. O ápice desta autoexploração seria o soçobramento, ou seja, o esmorecimento neural, resultando nas patologias psíquicas típicas da sociedade enferma neoliberal. Crises em escala global são provocadas por instituições financeiras. O Fundo Monetário Internacional - FMI, por sua vez, solta dinheiro para os países juntamente com a cartilha da neoliberalização dura e supostamente eficiente, um pacote que inclui: desregulamentação das leis de trabalho, ausência do Estado no desenvolvimento de políticas públicas, uma economia reduzida ao rendimento no mercado de ações.

Uma de suas teses é que vivemos em um grande oráculo mercantil, supostamente transparente. $\mathrm{Na}$ infosfera, cada usuário vive a ilusão de ser um cibercidadão; todavia, somos supervisionados e governados pela lógica algorítmica. O autor aponta para uma mudança de valores na sociedade ocidental: aos poucos, estamos abandonando o direito à privacidade e à intimidade, para adentrarmos um estado de frenesi e de autoexposição permanente. Han advoga a necessidade do homo laborans voltar a ser o homo sapiens, defende o direito ao ócio e à vida contemplativa. Julga essencial refletirmos sobre que valores almejamos construir socialmente para superarmos o estágio de obnubilação a que estamos submetidos.

Na contramão da era das massas clássicas que se formavam a partir da agremiação de trabalhadores, sindicalistas, camponeses e estudantes, no livro No enxame: reflexões sobre o digital, Han (2016) analisa a hipercomunicação rizomática digital a partir do isolamento de cada usuário nas redes, aceitando também, a metáfora do rizoma para discutir o conceito de rede.

Seu argumento é que gigantes da comunicação como Google, Facebook, Twitter, operam como um serviço secreto do capitalismo digital. Muito além de uma aparente 
instituição que oferta entretenimento. A lógica de mercado dessas empresas está no interesse em desvendar o inconsciente de cada infonauta, seus hábitos e interesses, sua disposição para o consumo. A partir de cada informação disponibilizada de forma voluntária pelos usuários, a tecnologia do Big Data permite a elaboração de prognósticos sofisticados do comportamento da sociedade.

É preciso ressaltar que as análises tecidas pelo filósofo nesse livro foram escritas antes que viessem à tona as controvérsias em torno da eleição presidencial americana de 2016 ${ }^{6}$, bem como o plebiscito do Brexit (Reino Unido). Nesses dois casos, a partir das análises dos perfis hospedados na rede social Facebook, traçou-se uma descrição psicopolítica em profundidade de cada usuário, permitindo que empresas de marketing desenvolvessem narrativas personalizadas, estruturadas a partir das percepções e preferências que cada usuário registrava na rede social.

Outra preocupação que aparece na obra são os chamados movimentos ciberativistas, que se formam a partir das conexões e interações em rede. Para o autor, essas movimentações coletivas instáveis, efêmeras, muitas vezes "carnavalescas" (HAN, 2016, p. 24), sem qualquer reflexão crítica sobre a ditadura da informação instaurada no contexto atual, estão nos levando a uma sociedade de vigilância ubíqua.

Sendo assim, o psicopoder é mais eficaz que o biopoder, uma vez que não é de fora, mas de dentro, que vigia, controla e age sobre os seres humanos. A psicopolítica digital apodera-se do comportamento social das massas, uma vez que baseia na sua lógica inconsciente. A sociedade da vigilância digital, com acesso ao inconsciente e aos futuros comportamentos sociais da massa, adquire traços totalitários. Submetenos à programação e aos controles psicopolíticos. A era biopolítica ficou para trás. Hoje avançamos rumo à era da psicopolítica digital. (HAN, 2016, p. 92).

Para o filósofo, as ondas de indignação que surgem nas redes são dotadas de um debate político precário e reduzido. As bolhas digitais impedem que os internautas

\footnotetext{
${ }^{6}$ A primeira versão do livro foi publicada em Berlim no ano de 2013.
} 
possam compreender as novas dinâmicas do capitalismo digital: sua coerção na redução do estado democrático de direito, bem como o asfixiamento dos direitos sociais.

Para Han, ao invés do Big Brother descrito no romance de George Orwell, a cultura digital instaurou o Big Data (as grandes bases de dados formadas a partir das interações que os internautas tecem na rede). Sobre o obscuro mercado de vendas de informações dos infonautas, o autor cita como exemplo o desempenho financeiro da Acxiom, uma das principais empresas dos Estados Unidos especializada na tecnologia Big Data. Em 2013, a organização obtinha um protocolamento total da vida de mais de 300 milhões de americanos. A empresa, que possui mais informações dos americanos que o FBI, obteve no referido ano um dos desempenhos financeiros mais extraordinários de Wall Street.

Para o filósofo, o grande dilema que está posto nesse enxame efêmero digital é a falta de clareza de como os algoritmos interferem e modificam a arquitetura das redes. Os estudos que se debruçaram a analisar essa temática até o momento apontam que gigantes da comunicação têm apostado todas as suas fichas no aprimoramento do design tecnológico, na tentativa de compreender a bolha social a que cada internauta pertence, bem como traçar com precisão seus hábitos e costumes - informações estratégicas para o avanço do capitalismo digital ${ }^{8}$.

Uma análise filosófica sobre as novas técnicas de poder instauradas no capitalismo digital é sistematizada no livro Psicopolítica (HAN, 2015). A principal tese defendida na obra é a de que, na cultura digital, os usuários da rede não têm consciência de sua submissão. Para o autor, a eficiência do psicopoder baseia-se principalmente no fato de que os internautas imaginam ser livres, quando, na realidade, o sistema explora a sua liberdade. Para Han, a eficiência do psicopoder está calcada no acesso que tem à psique das pessoas (o que na era do biopoder não era possível).

O termo psicopoder é desenvolvido a partir das obras de Foucault (1999) e Deleuze (1992). O filósofo advoga não ser possível analisar a atual sociedade conectada à luz da

\footnotetext{
7 Termo desenvolvido pelo autor para se referir à vigilância em massa instaurada pelo Big Data. Somos vigiados não mais por câmeras, mas também por outros objetos ao nosso redor, por coisas que usamos cotidianamente, ou situações que deixamos de executar.

${ }^{8}$ Corroboram essa argumentação, Kaufman (2019) e Santaella (2018).
} 
biopolítica. Diante de tal perspectiva, a psicopolítica adentra as engenharias computacionais, bem como as interligações dos cookies ${ }^{9}$, que deixaram transparentes todas as nossas movimentações na web. Torna-se urgente discutir a crise de liberdade na qual nos encontramos.

Estamos a caminho da época da psicopolítica digital. Avançamos na via que leva de uma vigilância passiva a um controle ativo. O que nos precipita numa crise da liberdade de alcance máximo, pois que afeta agora a própria vontade livre. O Big Data é um instrumento psicopolítico extremamente eficaz que permite adquirir um conhecimento integral da dinâmica inerente à sociedade da comunicação. Trata-se de um conhecimento de dominação, que permite intervir na psique e condicionála a um nível pré-reflexivo. A abertura do futuro é constitutiva da liberdade de ação. Todavia, o Big Data permite fazer prognósticos sobre o comportamento humano. O futuro torna-se assim predizível e controlável. (HAN, 2015, p. 21).

Para o autor, não restam dúvidas de que a automação e a robótica deixaram o chão de fábrica menos insalubre. Todavia, os artefatos digitais trouxeram uma nova escravatura. Uma exploração mais intensa e eficaz, tendo em vista que, agora, a ubiquidade transforma qualquer lugar em posto de trabalho. A técnica de poder inteligente instaurada com o advento do Big Data não utiliza os métodos repressores da sociedade disciplinar. Está em jogo a tentativa de desvendar a psique, o subconsciente do infonauta. Para isso, não é imposta aos usuários da rede qualquer restrição, ao contrário, nas redes sociais somos instigados a tecer comentários sobre os mais variados assuntos de forma exaustiva. Facebook, Instagram, Twitter, Snapchat instigam a nossa participação. Diariamente somos motivados a compartilhar nossa localização, emitir uma opinião sobre determinado assunto, comunicar hábitos e interesses da nossa vida pessoal. Para Han, a psicopolítica não nega a liberdade, mas a explora. A partir do que digitamos nas redes sociais digitais, os algoritmos nos separam em categorias: vertente política, orientação sexual, gostos musicais, tendência religiosa, hábitos de lazer, hábitos de alimentação etc.

\footnotetext{
${ }^{9}$ Cookies são arquivos de texto que armazenam as preferências dos internautas através das várias páginas acessadas. Os webbeacons permitem que os sites coletem e transfiram informações dos usuários, quando estes clicam em alguma imagem ou link. Esses dispositivos são instrumentos de rastreamento utilizados pelos sites para traçar o perfil de cada usuário da rede (FUGAZZA; SALDANHA, 2017).
} 
As redes sociais digitais são apenas uma parte da sociedade vigilante à qual estamos expostos. O cadastro que cada consumidor faz na loja de sua preferência para adquirir um cartão de fidelidade alimenta uma base de dados. Quando informamos nosso CPF em uma farmácia para ganhar descontos nos produtos que estamos adquirindo, dados estão sendo gerados, softwares cruzam nossas preferências.

O segmento de cartão de crédito há muito tempo vem deixando em segundo plano suas atividades clássicas na área financeira. Mais de $60 \%$ do faturamento anual de empresas como Mastercard e VISA advêm de atividades relacionadas a Big Data e Inteligência Artificial.

A Mastercard Advisors agrega e analisa aproximadamente 65 bilhões de transações de 1,5 bilhões de titulares de cartão em 210 países, procurando identificar tendências de negócios e consumo para, em seguida, comercializar a informação a terceiros. [...] segundo a Febraban - Federação Brasileira de Bancos, atualmente $80 \%$ dos bancos que atuam no Brasil investem em inteligência artificial. (KAUFMAN, 2019, p. 58).

Um novo processo de "hibridização tecnológica", que permitirá uma "visão 360 " de cada indivíduo, está sendo aprimorado com uma sofisticação que se convencionou chamar de internet das coisas. Uma possibilidade de você ter artefatos tecnológicos comunicando-se entre si independentemente de nossa ação, ou seja, ter em nossas residências máquinas conversando com outras máquinas, dentro e fora de nossas casas.

Essa grande rede de $\operatorname{actantes}^{10}$ se organiza para supostamente atender aos nossos interesses. Nesse sentido, uma geladeira conectada, ao perceber a falta de determinados produtos, providenciará a compra automaticamente, sem a interferência humana. Se, por um lado, tratar-se de uma ação que nos deixa livres para fazer outras coisas, uma base de dados será gerada a partir de nossos hábitos alimentares.

Em um futuro não muito distante, todos os eletrodomésticos de nossa residência estarão interligados: torradeiras, geladeiras, máquina de lavar, micro-ondas. A infosfera

\footnotetext{
${ }^{10}$ Actante se refere a qualquer elemento conectado. Nessa perspectiva, uma rede pode ser formada por actantes humanos e não humanos.
} 
saberá a hora exata de nossa alimentação, o que comemos, bebemos, fazemos, onde estamos. O capitalismo digital avança nos impondo uma vida mercantilizada; somos expostos de forma permanente ao consumo, nas redes sociais digitais; nossos perfis são reduzidos a um objeto de publicidade que é avaliado pelo número de visualizações e curtidas.

Como a sociedade da informação se comportará a partir de 2020, quando a internet das coisas poderá conectar carros inteligentes, eletrodomésticos e smartphones? Quais as implicações psíquicas dessa sofisticada forma de controle? Quais as consequências sociais dos prognósticos precisos que os Big Datas farão a partir de todas as informações que disponibilizamos em plataformas como: Social Eyes, Waze, Timeline do Facebook, Social Cam, Hotlist, Open Graph e Plancast?

Uma análise filosófica dessas ambivalências permeia o livro $A$ sociedade da transparência (2014). Sua tese principal é que a transparência ganha evidência quando a confiança desaparece do convívio social. Diante de tal situação, se aposta na vigilância em massa e no controle para superar a crise ética típica da sociedade ocidental atual. Nas últimas décadas, com o fim de ditaduras militares em vários países, acordos sociais foram firmados para tornar as ações dos governantes mais transparentes.

O discurso da transparência adentrou os meios de comunicação de massa, escolas e universidades. Com a popularização do acesso à internet, hoje, nos países emergentes, temos uma geração que acredita que a privacidade se tornou obsoleta, se trata de um valor do milênio passado. Para o autor, as mídias sociais e seus motores de busca personalizados

[...] erigem na rede um espaço próximo absoluto, do qual o fora foi eliminado. É um espaço onde nos encontramos somente a nós mesmos e aos que se assemelham a nós. Não há qualquer negatividade que torne uma mudança possível. Esta proximidade digital não apresenta ao participante senão essas secções do mundo ao seu gosto. Desse modo, desintegra a esfera pública, a consciência pública, crítica, privatizando o mundo. A rede transforma-se numa esfera íntima, ou numa zona de bemestar. A proximidade, da qual toda a distância de longe foi eliminada, é também uma forma de expressão da transparência. (HAN, 2014, p. 54). 
Ao contrário das promessas comunitárias anunciadas três décadas atrás, na atual sociedade da transparência estamos diante de uma "vertigem digital". Vivemos ansiosos, desorientados, fragmentados em bolhas. Somos ator e vítima ao mesmo tempo.

No Brasil, causou grande repercussão a reportagem de Aiuri Rebello publicada no jornal Folha de São Paulo em 16/01/201911, trazendo detalhes da visita que a bancada de parlamentares do PSL - Partido Social Liberal - fez à China para conhecer o sistema digital de reconhecimento de rostos de cidadãos. A viagem foi custeada pelo governo chinês, pois este tem interesse em comercializar o produto; um dos objetivos dos deputados era a apresentação de um Projeto de Lei na Câmara dos Deputados para discutir a implantação de tal tecnologia no Brasil. A cidade-piloto para avaliar essa sofisticação tecnológica seria o Rio de Janeiro.

O sistema de monitoramento chinês consiste em sofisticado conjunto de câmeras espalhadas por pontos estratégicos (metrôs, escolas, aeroportos) e outras móveis, embutidas em óculos de profissionais que cuidam da segurança pública. Quando o rosto de um indivíduo é capturado por uma câmera, em apenas sete minutos o sistema do governo apresenta: nome completo do cidadão, idade, gênero, bens que estão em seu nome, rotas mais frequentes que ele realiza, local de trabalho, parentes e as pessoas com as quais o indivíduo monitorado interagiu nas redes sociais digitais.

No meio acadêmico não faltam críticas ao Partido Comunista Chinês ${ }^{12}$. Para alguns analistas, o regime ditatorial se utiliza do sistema digital para promover uma vigilância em massa dos cidadãos chineses. Já os parlamentares brasileiros consideram a vigilância da sociedade, bem como a atualização da legislação brasileira, um caminho irreversível. Advogam ainda que a segurança pública no Brasil precisa de um "choque" e acreditam

\footnotetext{
11 A versão digital da reportagem pode ser conferida em https://www1.folha.uol.com.br/mercado/2019/01/bancada-do-psl-vai-a-china-importar-sistema-quereconhece-rosto-de-cidadaos.shtml. Acesso em: 17 jan. 2019.

${ }^{12}$ A literatura sobre o assunto é vasta. Indica-se, em especial, a produção do filósofo Luciano Floridi, da Universidade de Oxford. No Brasil, a coletânea Tecnopolíticas da Vigilância, organizada por Fernanda Bruno et al. (2018), evidencia que especialmente nas cidades que receberam os jogos da Copa do Mundo da FIFA, em 2014, os centros de monitoramento implantados - com exceção do Rio de Janeiro, os demais estão em funcionamento até hoje - não destoam muito do modus operandi do sistema de vigilância chinês.
} 
que a sofisticação tecnológica chinesa é o indutor necessário para restabelecer a ordem no país.

Em um longo artigo, no qual analisa como o aparato estatal de vigilância foi eficaz no combate à Pandemia do Coronavírus na Ásia - China, Hong Kong, Taiwan, Singapura Han (2020) retoma a discussão da ambivalência vigilância versus privacidade. Se por um lado, esse aparato tecnológico permitiu que rapidamente as autoridades sanitárias identificassem quem estava infectado com a Covid-19 - a medida que um cidadão testava positivo, o sistema de vigilância chinês apontava com quem o indivíduo interagiu nos últimos dias e automaticamente, essas pessoas recebiam mensagens em seus celulares, informando que elas deveriam comparecer imediatamente a uma unidade de saúde para realização do exame - por outro, o regime chinês demonstrou aos chefes de Estado do ocidente, mais uma razão, para que sua tecnologia seja exportada.

Na China não há nenhum momento da vida cotidiana que não esteja submetido à observação. Cada clique, cada compra, cada contato, cada atividade nas redes sociais são controlados. Quem atravessa no sinal vermelho, quem tem contato com críticos do regime e quem coloca comentários críticos nas redes sociais perde pontos. A vida, então, pode chegar a se tornar muito perigosa. Pelo contrário, quem compra pela Internet alimentos saudáveis e lê jornais que apoiam o regime ganha pontos. Quem tem pontuação suficiente obtém um visto de viagem e créditos baratos. Pelo contrário, quem cai abaixo de um determinado número de pontos pode perder seu trabalho. (HAN, 2020, p. 3).

De acordo com o autor, no referido país, conceitos como: privacidade e direitos dos infonautas não fazem parte do vocabulário chinês. Os cidadãos também costumam ser mais obediente a seus governantes em relação aos países do ocidente. O filósofo teme que situações adversas como a humanidade está enfrentando em 2020 - Pandemia do Coronavírus - seja um prelúdio para disseminação de sistemas totalitários ao redor do globo. 


\section{Múltiplas narrativas em disputa da verdade}

Em 2016, com o plebiscito que ocorreu no Reino Unido (Brexit), quando os eleitores referendaram a saída daquele país da União Europeia, bem como a inesperada vitória de Donald Trump à presidência dos Estados Unidos ${ }^{13}$, a expressão "pós-verdade" se popularizou nas redes e nos meios de comunicação de massa. O que se convencionou denominar de fenômeno da "pós-verdade" trata-se de histórias inverídicas, todavia formuladas intencionalmente para atingir a reputação de terminado indivíduo, contendo alguns pontos realísticos e outros distorcidos. Essas narrativas de forte apelo emocional muitas vezes "viralizam" nas redes, tendo mais impacto que uma notícia jornalística bem apurada, bem como uma informação de caráter científico.

Como muito bem ressalta Mans (2018, p. 07), o termo "pós-verdade" não é novo. Na academia apareceu pela primeira vez quando Steve Tesich, em 1992, publicou um artigo na revista The Nation, denunciando as falhas cometidas durante a cobertura jornalística na Guerra do Golfo. Em 2004, o termo voltou a ser discutido, diante da publicação do livro $A$ era da Pós-Verdade: Desonestidade e enganação na vida contemporânea (KEYS, 2004). Nessa obra, o autor destaca que, embora mentiras e boatos sempre estivessem ao lado do percurso evolutivo da humanidade, na contemporaneidade, com o crepúsculo ético dos meios de comunicação de massa, "vivemos uma era da pós-verdade" (KEYS, 2004, p. 20).

\footnotetext{
${ }^{13}$ Leitores interessados nas teorizações sobre as técnicas de classificação de personalidade com base nos rastros que os usuários registram voluntariamente nas redes sociais digitais podem conferir as análises: RESNICK, Brian. This psychologist's "gaydar" research makes us uncomfortable: that's the point. Vox.com. 29 jan. 2018. Disponível em: <https://www.vox.com/science-and-health/2018/1/29/16571684/> e DALLASTA DEL GROSSI, Viviane Ceolin. Proteção de dados na era tecnológica: rumos da regulamentação, privacidade e impactos sociais. In: COMITÊ GESTOR DA INTERNET NO BRASIL - CGI.br. Pesquisa sobre o uso das tecnologias de informação e comunicação no Brasil: domicílios brasileiros 2018. São Paulo: Comunicação Nic.br, 2019. O modelo criado pelo pesquisador da Universidade Stanford, Michal Kosinski, foi aprimorado pela consultoria Cambridge Analytica na campanha presidencial de Donald Trump e vem sendo replicado em várias eleições presidenciais na América do Sul, Ásia e Europa. Na América Latina, o pesquisador da Universidade Autônoma de Buenos Aires Ariel Goldstein (2019) analisa o uso desse "modus operandi" tecnológico por grupos de extrema direita no Brasil, Alemanha, Hungria, Polônia, Itália e Eslovênia. Sobre as eleições gerais de 2018 que ocorreram no Brasil, estudo empírico realizado pelos pesquisadores Viktor Chagas, Michelle Modesto e Dandara Magalhães (2019) analisa 11.118 mensagens trocadas em 158 grupos de WhatsApp de apoio à candidatura de Bolsonaro. Um dos dados mais significativos constatados pelos autores é que a retórica do medo foi um elemento estratégico para mobilizar grupos populacionais específicos a se engajarem na campanha presidencial do candidato.
} 
Os objetos de análise do autor são as coberturas que o jornalismo americano realizou em episódios famosos como: Watergate, Guerra do Vietnã, Guerra Irã e Iraque. Em sua análise, a ausência de uma educação para a promoção da cidadania e da ética tem contribuído para a formação de uma sociedade da encenação, em que a desonestidade é encorajada pelos mais variados setores. Pessoas supostamente livres aceitam passivamente viver em um admirável mundo de ilusões, ou seja, uma sociedade "pósverídica".

É fato que, como adverte Amaral (1996), os valores mais caros ao jornalismo são a imparcialidade e a neutralidade. Independentemente do veículo de comunicação, a narrativa estruturada é carregada de conceitos que o profissional desenvolveu ao longo da sua trajetória. Nas análises, estão implícitas características de quem escreveu: classe social, orientação sexual, vertente política. Por muito tempo, as regras deontológicas formuladas nos códigos de ética profissional foram a solução encontrada para amenizar esses dilemas.

Todavia, com a cultura digital, novos problemas emergiram. Se antes da popularização da internet, a comunicação de massa se estruturava em um número restrito de produtores (rádio, TV, jornal, revista) atingindo muitos receptores (ouvintes, telespectadores, leitores), o advento da internet embaralhou essa estrutura. Atualmente, com os blogs, aplicativos e redes sociais digitais, temos muitas pessoas produzindo para muitos internautas. Obviamente que a qualidade e o rigor dessas produções têm sido objeto de discussão pelos mais variados setores da sociedade, atingindo seu clímax em 2016, com as denominadas "fake news", expressão cunhada pela imprensa estadunidense para se referir às notícias fraudulentas que permearam o pleito eleitoral daquele país, em 2016.

As expressões "pós-verdade" e "fake news" têm sido fortemente criticadas pela academia, classificadas como insuficientes para compreender os fenômenos sociológicos atuais. O leitor interessado no assunto encontra boas análises no dossiê "Pós-verdade e jornalismo", publicado pela Revista USP nº 116 (2018) $)^{14}$. Lúcia Santaella (2018), em

\footnotetext{
${ }^{14}$ Revista USP. Dossiê pós-verdade e jornalismo, n. 116, 2018. Disponível em: http://www.revistas.usp.br/ revusp/ issue/view/10663. Acesso em: 25 fev. 2020.
} 
excelente diagnóstico sobre o tema, aposta na educação e no rigor científico para superar as inverdades disseminadas nos ambientes virtuais.

Isso tudo não revela outra coisa senão a crise de valores provocada, entre outros fatores, pela sobredeterminação que a emoção exerce na racionalidade humana, pela ausência do debate público e de formas de consenso que as redes sociais pulverizaram, em suma, problemas que o ajuste de algoritmos, por si só, não consegue resolver e que, ao fim e ao cabo, evidenciam o sintoma maior, para o qual muitos especialistas têm chamado a atenção: o desfalque das democracias representativas. (SANTAELLA, 2018, p. 52-53).

Nessa guerra de informações e contrainformações, estudos têm identificado que quanto mais um internauta é exposto a um boato viralizado nas redes sociais digitais, aumenta a chance deste considerar aquela informação verdadeira (CASTRO, 2018, p. 62). Pelo mundo, diversos debates têm sido protagonizados na tentativa de formular soluções para superar o "tsunami das inverdades".

A Organização para a Cooperação e Desenvolvimento Econômico - OCDE formulou um teste de competências que visa à mensuração da capacidade de pensamento crítico dos jovens internautas na escolha das fontes de informação. $O$ protocolo está sendo testado em várias escolas de educação básica, em diferentes regiões do globo (RAIS, 2018). O Fórum Econômico Mundial de Davos se referiu à desinformação generalizada praticada nos ambientes cibernéticos como uma ameaça ao convívio em sociedade. Em conferência que tratou do assunto, os pesquisadores consideraram que o 'incêndio digital' representa uma ameaça à estabilidade do planeta (HOWELL, 2013, p. 34).

Parte desses diagnósticos formulados até o momento apontam a educação como caminho para superação desse estado de frenesi instaurado pela sociedade hiperconectada. Obviamente que é preciso construir novas metodologias para abordar esse assunto em sala de aula, ir além da abordagem tecnológica instrumental. É preciso instigar nossos jovens a refletirem sobre a dimensão ética, estética e política das redes, 
um desafio complexo nos países da periferia do capitalismo, onde a maioria dos usuários da rede desconhece as noções básicas de como a internet está estruturada.

\begin{abstract}
Um dos maiores problemas relativos às bolhas consiste em que a grande maioria dos usuários das redes não tem a menor ideia acerca de como as mídias, especialmente as mídias digitais, funcionam. Adquirem os dispositivos, instalam os aplicativos de seu interesse, fazem uso dos benefícios que lhes são oferecidos sem qualquer preocupação com as perdas que sofrem e os riscos que correm. Os recursos são utilizados em horizontes aparentemente abertos, no desconhecimento de que esses horizontes estão se configurando em bolhas cada vez mais impermeáveis. (SANTAELLA, 2018, p. 24).
\end{abstract}

Para além dos discursos distópicos, que para jovens internautas podem soar como mensagens cívicas de pastores no púlpito, a educação precisa construir processos cognitivos mais amplos, que conduzam os estudantes ao aprimoramento dos aspectos relacionados à sensibilidade, ao cuidado de si, bem como à responsabilidade social fatores básicos que nos constituem como humanos.

A customização dos ambientes informáticos sob a égide dos algoritmos oferece um mundo encantado, adaptado ao interesse de cada usuário. As redes sociais, criadas inicialmente para instigar debates e colaboração, nos últimos anos se converteram em um espelho estável, repleto de perfis que pensam exatamente como nós. Caso seja do interesse de um determinado usuário nunca mais ler notícias sobre a temática pobreza, este não irá visualizar nada a respeito (PARISIER, 2011, p. 42). É diante de tais paradoxos que a ética aplicada nos oferece elementos epistemológicos para enfrentarmos os dilemas da cultura digital.

É importante ressaltar que compreendemos a ética como uma reflexão filosófica sobre a moral. Assim, também é oportuno esclarecer a diferença entre ética e moral, embora os dois termos sejam comumente utilizados como sinônimos. A moral pode ser compreendida como um conjunto de normas, crenças e valores que conduz a vida prática em uma determinada sociedade. Já a ética, como um campo de estudo dentro da filosofia, se propõe a analisar e a justificar - com base em critérios e argumentos - quais 
são ou deveriam ser as ações corretas no âmbito moral. Desde a Antiguidade até a contemporaneidade, várias foram as teorias éticas formuladas, a exemplo da ética de virtudes, éticas do dever, éticas utilitaristas, ética do discurso, dentre outras (BORGES; DALL'AGNOL; DUTRA, 2003; CORTINA, 2003; CORTINA; MARTÍNEZ, 2013).

Nesse sentido, a filosofia nos mostra que os valores estabelecidos em cada período histórico sempre foram um campo de disputas. O que se considera moral no ano de 2020 tem pontos distintos do acordo social estabelecido nas primeiras décadas do século XX. As normas sociais foram formuladas a partir dos interesses de setores dominantes: políticos, econômicos e sociais. Ao mesmo tempo, debates foram sendo estabelecidos nos diversos fóruns - sindicais, parlamentares, organizações não governamentais -, no sentido de reforçar ou enfraquecer determinado valor a partir das lutas travadas nos espaços de poder. Conforme a sociedade foi se transformando, acordos estabeleceram regras em como lidar com o meio ambiente, como dirimir os embates travados nas trocas comerciais, bem como os conflitos estabelecidos nas relações trabalhistas. Dessa forma, as diferentes vertentes éticas estão em constante aprimoramento, ou, em outras palavras, é exatamente a reflexão ética que proporciona a revisão do que se considera moral a partir dos embates e críticas que impulsionam mudanças na escala dos valores sociais.

Nesse sentido, a ética aplicada nasce diante da necessidade de respostas para os problemas presentes no cotidiano. Comumente, as éticas aplicadas não se detêm a examinar os princípios de uma única teoria ética, mas se pode dizer que bebem de diversas fontes, conjugando elementos e princípios de teorias diversas que ajudam a trazer respostas aos problemas concretos de uma determinada área (BORGES; DALL'AGNOL; DUTRA, 2003).

Assim, neste ensaio, buscamos pensadores que têm contribuído com o desenvolvimento teórico da chamada 'Infoética' ou ética da informação, os quais nos chamam atenção para a necessidade de uma adequada reflexão ética sobre o uso das tecnologias digitais, bem como seus impactos, sobretudo com o avanço exponencial da nanotecnologia, da inteligência artificial e da governança cibernética sob a égide dos algoritmos. Liberdade de expressão, censura, inclusão digital, vício e dependência dos 
ambientes informacionais, responsabilidade e proteção dos dados pessoais dos internautas são algumas das preocupações. No geral, são pensadores que assumem como inalienáveis valores tais como: autonomia, liberdade, proteção à vida, condenação a toda forma de tortura e escravidão, respeito à privacidade, bem como defesa da democracia, situando seus debates no contexto desses valores. Na sequência, procura-se sintetizar os pontos principais das discussões que esses autores têm trazido sobre a dimensão ética do uso das redes e das tecnologias digitais.

Com o avanço da inteligência artificial, os países da periferia do capitalismo passaram a sofrer uma intensificação do colonialismo, bem como uma opressão digital em favor do lucro corporativo. Se na Revolução Industrial a produção de mercadorias era a principal locomotiva do sistema capitalista, no capitalismo digital, o comércio obscuro de dados informacionais se tornou o negócio mais rentável da indústria 4.0.

Diante do avanço da cultura digital, o filósofo Luciano Floridi (2006) considera que a privacidade informacional precisa ser pensada como um valor inalienável semelhante ao direito à vida e à liberdade. Sobre as primeiras tentativas de debater sobre o assunto, aponta que é preciso considerar o ciclo completo da informação, que inclui a sua criação, processamento, distribuição, armazenamento, proteção, uso e possível destruição.

A privacidade está intrinsecamente relacionada com a autonomia informacional (CAPURRO, 2009; FLORIDI, 1999). Na atual estrutura das redes, em que algoritmos e cookies selecionam que conteúdo mostrar a determinado usuário, a liberdade dos internautas está sendo violada, tendo em vista que as bolhas digitais tendem a mostrar apenas conteúdos que reforçam a fidelidade do infonauta ${ }^{15}$. Se um jovem tem o hábito de passar algumas horas do dia assistindo a vídeos de luta na plataforma YouTube, toda vez que o usuário acessa o referido site, os algoritmos dessa rede social irão mostrar prioritariamente vídeos relacionados a essa temática. A mesma lógica é utilizada para expor o internauta ao consumo. A partir do que você digita nas redes sociais digitais, anúncios relacionados às conversas tecidas começam a surgir no seu e-mail.

\footnotetext{
15 Usuário imerso nas redes. Um internauta pode apenas acessar esporadicamente de forma instrumental o ciberespaço. O infonauta, por sua vez, é um usuário imerso, previdente, conhece em profundidade as infovias da rede (SANTAELLA, 2004).
} 
Infelizmente, na cultura digital, temos assistido ao enfraquecimento do valor da privacidade e ao reforço do exibicionismo. Redes sociais como Facebook e Instagram nos instigam a uma exposição permanentemente. Diante de tal paradoxo,

a agenda do direito à proteção à privacidade na Internet não ganha a visibilidade devida diante dos crescentes problemas envolvendo esta temática na contemporaneidade; diferentemente do que ocorre, por exemplo, com os movimentos em prol da ampliação de acesso à rede. Isto é agravado diante da realidade de ações estratégicas de personalização e filtragem de conteúdo operacionalizada pelas empresas digitais para potencialização do lucro corporativo, facilitando sobremaneira o amplo acesso que elas possuem sobre as informações dos internautas, o que limita as possibilidades de liberdade e autonomia neste ambiente. (FUGAZZA; SALDANHA, 2017, p. 99).

Diante de tais condicionantes, torna-se urgente refletir na filosofia informacional que valores são importantes para interagir de forma ética nas redes. Uma das teses que vem sendo debatida no campo da ética aplicada é que a boa vontade individual pode ter consequências desastrosas para a coletividade. Por isso a necessidade de superar a reflexão dos valores no campo individual. É preciso pensar no bem-estar coletivo levando em consideração os cidadãos, as instituições e as organizações do Estado.

Ao fazer um excelente estado da arte sobre os paradoxos da cultura da transparência, Derrick de Kerckhove (2016) aponta que, na contemporaneidade, nossos jovens já têm contato com as redes sociais digitais desde a infância. Antes mesmo que eles possam compreender com clareza os valores que garantem o bom convívio em sociedade, suas interações na internet são capturadas pelos cookies, transformando-se em estatísticas que alimentam alguma base de dados. Diante de tal perspectiva, o autor indaga que valores devem prevalecer na era digital para evitar a tirania que já nos assolou em regimes ditatoriais. Tendo por base suas pesquisas desenvolvidas no Canadá, o professor da Universidade de Toronto identifica quatro paradoxos na relação que os jovens estabelecem com as redes: 
Vida privada: embora estejam bem conscientes dos riscos envolvidos, os jovens ainda publicam informação sobre si mesmos sem preocupação, incluindo informação que pode ser considerada "sensível" sob o aspecto da privacidade. Controle: os jovens pedem para ter controle sobre seus dados pessoais, mas se preocuparam pouco e não atualizam as ferramentas de proteção de anonimização, criptografia, etc. (tecnologias que aumentam a privacidade, ou Privacy Enhancing Technologies-PET). Responsabilidade: os jovens consideram que a responsabilidade de proteger os seus dados pessoais deve ser compartilhada entre o Estado, as empresas e si mesmos, mas não acredito que isso seja feito corretamente. O Estado parece muito distante, os negócios não são confiáveis, e em relação a si próprios, os jovens alegam que não têm tempo nem competência. Consciência: as disposições legais para a proteção de dados pessoais não são bem conhecidas nem estão totalmente aceitadas e têm menos influência no comportamento dos jovens do que a sua própria experiência diária. (KERCKHOVE, 2016, p. 7).

Diante de tais paradoxos, o pesquisador aponta alguns pilares para consolidação de uma ética da informação: 1) no campo jurídico, é preciso leis mais efetivas que regulem e garantam a proteção dos dados dos usuários da rede; 2) na área da ciência da informação, é preciso desenvolver e disponibilizar ferramentas que garantam um nível razoável de privacidade; 3) os currículos educacionais devem ir além da abordagem instrumental; apenas orientar em como utilizar um determinado artefato tecnológico não é suficiente diante dos dilemas da sociedade da informação; 4) a mediação dos professores deve considerar os valores necessários para a ação consciente na sociedade hiperconectada. Os jovens precisam ter clareza dos riscos e benefícios embutidos nas tecnologias digitais.

Aos educadores é preciso singularizar as experiências que os jovens internautas desenvolvem nas redes ao invés de generalizá-las. Nessa perspectiva, a dimensão ética é marcada pela reflexão dos valores, das leis, dos costumes, bem como da acelerada sociedade conectada em que estamos vivendo no capitalismo digital. A dimensão estética aposta no desenvolvimento de outras habilidades, capazes de intervir nos fluxos e nos modos de ser e fazer, provocando outros processos subjetivos, estes processuais e singularizantes. Já a dimensão política está focada na luta contra as formas de dominação - neocolonial, tecnológica e subjetiva - que se ocultam atrás dos sistemas informatizados e das telas dos dispositivos tecnológicos. 
Diante de tais paradoxos, Frank Pasquale (2015) problematiza a dimensão ética dos novos métodos de análise das empresas de planos de saúde, para aceitar ou recusar a adesão de novos clientes, bem como definir os preços das mensalidades. O processo decisório por parte da seguradora leva em consideração, inclusive, o histórico de compras do 'futuro segurado' nas farmácias. No estudo realizado, há um caso emblemático de uma mulher que havia consumido por muitos anos antidepressivos que a ajudavam na regulação do sono. Tendo por base esse histórico de compras nas farmácias registradas em seu CPF, a seguradora negou a comercialização do plano de saúde, alegando seu prolongado uso de "drogas". Embora o uso desses medicamentos tenha sido devidamente recomendado por um médico especialista para fins sanitários, o plano de saúde tratou a questão como "uso de entorpecentes".

Como já discutido ao longo deste artigo, o Big Data, ao lado das autoridades sanitárias, se mostrou muito eficiente no combate à Pandemia do Coronavírus em alguns países da Ásia. O debate que precisa ser aprofundado por parte da academia é como enfrentar as desigualdades tecnológicas. No Brasil, por exemplo, apenas 50\% dos domicílios dispõem de internet banda larga (REIS, 2020).

Por fim, um debate que não pode sair do horizonte acadêmico diz respeito aos aspectos que envolvem a participação social. Como apontou Han (2020), na China, o Big Data tem sido utilizado para fortalecer o regime ditatorial em curso naquele país. A jovem democracia brasileira corre riscos com a disseminação dessas novas sofisticações tecnológicas?

\section{Referências}

AMARAL, Luiz. A objetividade jornalística. Porto Alegre: Sagra Luzzatto, 1996.

BENTHAM, Jeremy. O panóptico. In: SILVA, Tomaz Tadeu da (org.). O panóptico/Jeremy

Bentham. Belo Horizonte: Autêntica, 2000.

BORGES, Maria de Lourdes; DALL'AGNOL, Darlei; DUTRA, Delemar Volpato. Ética. Rio de Janeiro: DP\&A, 2002. 
BRUNO, Fernanda; CARDOSO, Bruno; KANASHIRO, Marta; GUILHON, Luciana; MELGAÇO, Lucas. Tecnopolíticas da vigilância: perspectivas da margem. São Paulo: Boitempo, 2018. (Coleção Estado de Sítio).

CHAGAS, Viktor; MODESTO, Michelle; MAGALHÃES, Dandara. O Brasil vai virar Venezuela: medo, memes e enquadramentos emocionais no WhatsApp pró-Bolsonaro. ESFERAS, $v$. 14, p. 1-17, 2019.

CASTELLS, Manuel. Communication power. Cambridge: MIT, 2010.

CASTELLS, Manuel. A Sociedade em rede - a era da informação: economia, sociedade e cultura. São Paulo: Paz e Terra, 2002. V. I.

CASTELLS, Manuel. The rise of network society. Oxford e Malden: Blackwell, 1996.

CASTELLS, Manuel. The power of identity. Oxford e Malden: Blackwell, 1997.

CASTELLS, Manuel. End of millennium. Oxford e Malden: Blackwell, 1998.

CAPURRO, Rafael. Ética intercultural de la información. In: GOMES, Henriette Ferreira; BOTTENTUIT, Aldinar Martins; OLIVEIRA, Maria Odaisa Espinheiro de (orgs.). A ética na sociedade, na área da informação e da atuação profissional: o olhar da Filosofia, da Sociologia, da Ciência da Informação e da formação e do exercício profissional do bibliotecário no Brasil. Brasília: Conselho Federal de Biblioteconomia, 2009. p. 43-64. Disponível em: http://www.cfb.org.br/popup/a_etica.pdf. Acesso em: 03 fev. 2020.

CASTRO, Leandro Nunes de. Computação e desinformação: tecnologias de detecção de desinformação on-line. In: RAIS, Diogo (org.). Fake News: a conexão entre a desinformação e o direito. São Paulo: Thomson Reuters do Brasil, 2018. p. 61-73.

CORTINA, Adela. O fazer ético: guia para educação moral. São Paulo: Moderna, 2003.

CORTINA, Adela; MARTíNEZ, Emílio. Ética. 5. ed. Tradução de Silvana Cabucci Leite. São Paulo: Edições Loyola, 2013.

DELEUZE, Gilles. Conversações. Traduzido por Peter Pal Pelbart. Rio de Janeiro: Editora 34, 1992.

FOUCAULT, Michel. História da sexualidade I: a vontade de saber. Lisboa: Relógio D’Água, 1999.

FLORIDI, Luciano. “Ética de la información: su naturaleza y alcance”. Isegoría, Madrid, n. 34, p. 19-46, jun. 2006. 
FLORIDI, Luciano. Information ethics: on the philosophical foundation of computer ethics. Ethics and Information Technology, v. 1, n. 1, p. 33-52, mar. 1999.

FUGAZZA, Grace Quaresma; SALDANHA, Gustavo Silva. "Privacidade, ética e informação: uma reflexão filosófica sobre os dilemas no contexto das redes sociais". Encontros Bibli: Revista Eletrônica de Biblioteconomia e Ciência da Informação, v. 22, n. 50, p. 91-101, set./dez. 2017.

GOLDSTEIN, Ariel. A ascensão da extrema direita e o uso das redes sociais no brasil. Ciudad Autónoma de Bueno Aires: Instituto de Estudios de América Latina y el Caribe, Facultad de Ciencias Sociales, 2019.

GREENWALD, Glenn. Sem lugar para se esconder: Edward Snowden, a NSA e a espionagem do governo americano. Tradução de Fernanda Abreu. Rio de Janeiro: Primeira Pessoa, 2014.

HAN, Byung-Chul. Sociedade do cansaço. Tradução de Enio Paulo Giachini. Petrópolis: Vozes, 2017.

HAN, Byung-Chul. No enxame: reflexões sobre o digital. Tradução de Miguel Serras Pereira. Lisboa: Relógio D’Água, 2016.

HAN, Byung-Chul. Psicopolítica: neoliberalismo e novas técnicas de poder. Tradução de Miguel Serras Pereira. Lisboa: Relógio D’Água, 2015.

HAN, Byung-Chul. A sociedade da transparência. Tradução de Miguel Serras Pereira. Lisboa: Relógio D’Água, 2014.

HAN, Byung-Chul. Bom entretenimento: uma desconstrução da história da paixão ocidental. Tradução de Lucas Machado. Petrópolis: Vozes, 2019.

HAN, Byung-Chul. O coronavirus de hoje e o mundo de amanhã. Jornal El País Brasil, 22 mar. 2020. Disponível em: https://brasil.elpais.com/ideas/2020-03-22/o-coronavirus-dehoje-e-o-mundo-de-amanha-segundo-o-filosofo-byung-chul-han.html. Acesso em: 22 abr. 2020.

HOWELL, Louris. Digital wildfires in a hyperconnected world. Genebra: WEF Report, 2013.

KASTRUP, Virgínia. A rede, uma figura empírica da ontologia do presente. In: PARENTE, André (org.). Tramas da rede. Porto Alegre: Sulina, 2010. p. 80-90. 
KAUFMAN, Dora. A inteligência artificial irá suplantar a inteligência humana? Barueri: Estação das Letras e Cores, 2019.

KERCKHOVE, Derrick. Ética de transparência na era do Big Data. In: LOPES, Maria Immacolata Vassallo de; KUNSCH, Margarida Maria Krohling. Comunicação, cultura e mídias sociais. São Paulo: ECA/USP, 2016. p. 5-23.

KEYES, Ralph. A era da pós-verdade: desonestidade e enganação na vida contemporânea. Petrópolis: Vozes, 2004.

MANS, Matheus. A era da pós-verdade: onda de notícias falsas muda comportamento de pessoas e de empresas de tecnologia. Revista Br, v. 09, n. 14, p. 07-14, 2018. (Publicação do Comitê Gestor da Internet no Brasil).

PARENTE, André (org.). Tramas da rede. Porto Alegre: Sulina, 2004.

PARISIER, Eli. The filter buble: what the internet is hidding from you. London: Viking, 2011.

PASQUALE, Frank. The black box society: the secret algorithms that control money and information. Cambridge: Harvard University Press, 2015.

RAIS, Diogo (org.). Fake news: a conexão entre a desinformação e o direito. São Paulo: Thomson Reuters do Brasil, 2018.

REIS, Valdeci. Cenas juvenis na escola, na cidade e nas redes: notas etnográficas na ilha de Floriano e tantos outros ilhéus. 2020. 223f. Tese (Doutorado em Educação) - Programa de Pós-Graduação em Educação, Centro de Ciências Humanas e da Educação, Universidade do Estado de Santa Catarina, Florianópolis, 2020.

Revista USP. Dossiê pós-verdade e jornalismo, n. 116, 2018. Disponível em http://www.revistas.usp.br/revusp/issue/view/10663. Acesso em: 25 fev. 2020.

SANTAELLA, Lúcia. Comunicação ubíqua: representações na cultura e na educação. São Paulo: Paulus, 2013.

SANTAELLA, Lúcia. A cultura digital na berlinda. In: LOPES, Maria Immacolata Vassallo de; KUNSCH, Margarida Maria Krohling. Comunicação, cultura e mídias sociais. São Paulo: ECA/USP, 2016a. p. 93-101.

SANTAELLA, Lúcia. Temas e dilemas do pós-digital: a voz da política. São Paulo: Paulus, 2016b. 
SANTAELLA, Lúcia. A Pós-Verdade é verdadeira ou falsa? Barueri: Estação das Letras e Cores, 2018.

SANTAELLA, Lúcia. Navegar no ciberespaço: o perfil cognitivo do leitor imersivo. São Paulo: Paulus, 2004.

SNOWDEN, Eduard. Eterna vigilância. Tradução de Sandra Martha Dolinsky. São Paulo: Planeta, 2019.

SOUZA E SILVA, Adriana. Do ciber ao híbrido: tecnologias móveis como interfaces de espaços híbridos. In: ARAÚJO, Denize Correa de. Imagem (ir)realidade: comunicação e cibermídia. Porto Alegre: Sulina, 2006. p. 21-51.

ZUBOFF, Shoshana. Big Other: Capitalismo de vigilância e perspectivas para uma civilização de informação. In: BRUNO, Fernanda; CARDOSO, Bruno; KANASHIRO, Marta; GUILHON, Luciana; MELGAÇO, Lucas. Tecnopolíticas da vigilância: perspectivas da margem. São Paulo: Boitempo, 2018. (Coleção Estado de Sítio).

Recebido em: 28/02/2020

Aprovado em: 14/05/2020

Universidade do Estado de Santa Catarina - UDESC

Centro de Ciências Humanas e da Educação - FAED

Revista PerCursos

Volume 21 - Número 45 - Ano 2020

revistapercursos@gmail.com 